\title{
SCRUM: USO DE METODOLOGIAS ÁGEIS NA GESTÃO DE EQUIPES DE APOIO À EDUCAÇÃO A DISTÂNCIA
}

\author{
CHAPECÓ/SC JUNHO/2018
}

\author{
Ricardo Werlang - UCEFF - ricardowerlang@uceff.edu.br \\ Silviane Lawall Soares - UCEFF - silviane@uceff.edu.br \\ Jhon Lenon Ozório Alves - UCEFF - jhon@uceff.edu.br \\ Beatriz Moesch - UCEFF - beatriz.nead@uceff.edu.br \\ Matheus Martins Holscher - UCEFF - matheus.nead@uceff.edu.br
}

Tipo: Relato de Experiência Inovadora (EI)

Categoria: Gerenciamento e Logística

Setor Educacional: EDUCAÇÃO SUPERIOR

\begin{abstract}
RESUMO
A implantação de uma equipe de educação a distância (EaD) em uma instituição de ensino superior envolve diversas pessoas, de diferentes áreas e com diferentes competências e habilidades. Fazer com que essa equipe multidisciplinar e, algumas vezes, até geograficamente distantes, trabalhe de forma eficiente em conjunto não é uma tarefa muito simples. Ainda mais quando grandes projetos precisam ser realizados, enquanto as atividades diárias de atendimento e de solução de problemas não podem parar. O propósito deste trabalho é propor uma solução para gerenciamento de equipes como essas através do uso de metodologias ágeis e de ferramentas gratuitas. Neste trabalho, será detalhado uma solução para uso eficiente da metodologia ágil Scrum com as ferramentas Asana e Google Planilhas. Depois, será apresentado um relato de experiência do uso do Scrum na prática no dia a dia da equipe do Núcleo de Educação a Distância (Nead) da UCEFF, uma instituição de ensino superior privado do Oeste Catarinense, que atua em três campi nas cidades de Chapecó e Itapiranga. A aplicação do Scrum no Nead nitidamente aprimorou o nível de satisfação e de comprometimento da equipe, fazendo que mais projetos fossem realizados e em menos tempo.
\end{abstract}

Palavras-chave: Gestão de Equipes; Gestão de Projetos; Scrum; Nead, Metodologia Ágil, Educação à Distância

\section{AGRADECIMENTOS}

AGRADEÇO A EQUIPE NO NEAD DA UCEFF PELO ESFORÇO E DEDICAÇÃO QUE COLOCAM DIARIAMENTE NO TRABALHO. VOCÊS SÃO A PROVA DE QUE O SUCESSO SE ALCANÇA ATRAVÉS DE TALENTO, DETERMINAÇÃO E TRABALHO DURO. 


\section{1 - Introdução}

O processo de implantação e de gerenciamento de uma equipe multidisciplinar em uma Instituição de Ensino Superior (IES) é um grande desafio. Ainda mais quando essa equipe é composta por integrantes geograficamente distantes. Nesse contexto nasceu a equipe que compõe o Nead da UCEFF, uma instituição de ensino superior privado do Oeste Catarinense, que atua em três campi nas cidades de Chapecó e Itapiranga.

A equipe do Nead de uma IES é composta, muitas vezes, por designers educacionais, web designers, desenvolvedores, diagramadores, produtores audiovisuais, revisores e profissionais responsáveis pelo suporte e atendimento. Para que uma equipe como essa consiga entregar grandes projetos, como a produção do conteúdo de uma disciplina, por exemplo, o planejamento é uma etapa essencial. O maior desafio, contudo, consiste em encontrar uma metodologia que permita a realização de um planejamento flexível o suficiente para que os diferentes profissionais consigam evoluir no desenvolvimento de projetos maiores, mas que ainda consigam lidar com outras atividades que surgem por demanda do corpo discente, docente e de setores administrativos da IES.

Para um gestor, é muito tentador desenhar inúmeros diagramas, detalhando os processos e delegando responsabilidades diferentes para cada integrante da equipe. Contudo, sem uma comunicação eficiente e muito comprometimento, quando a equipe se depara com a realidade, cheia de imprevistos e demandas urgentes, os planos desabam. Outro fator complicador é a cultura organizacional, que muitas vezes costuma dar mais valor a formulários, procedimentos e reuniões do que à criação de valor concreto, que possa ser verificado a curtos intervalos de tempo pelas partes interessadas. Tendo como premissa que é loucura a realização de um trabalho que não resulta em valor, toda equipe deveria buscar um método de trabalho que evite o desperdício óbvio de esforço. Uma forma de fazer isso é trabalhar em ciclos curtos, que permitem a obtenção de um feedback logo no começo do projeto, entregando primeiro aquilo que levar mais valor às partes interessadas (SUTHERLAND, 2016).

Neste contexto, este trabalho propõe o uso de metodologias ágeis para gestão e planejamento de projetos de software, como o Scrum, na gestão de projetos de equipes multidisciplinares de uma IES, como é o caso de uma equipe que compõe o Nead. Para isso, apresentaremos os processos realizados para a implantação da metodologia Scrum no Nead da UCEFF, assim como um relato de experiência sobre como cada evento que compõe o Scrum é realizado por essa equipe, detalhando os processos e ferramentas utilizadas. Este trabalho pode ser utilizado como base para outras instituições que desejam implantar a metodologia Scrum em alguma de suas equipes. 
O restante do artigo está organizado da seguinte maneira. A seção 2 apresenta a motivação e alguns conceitos fundamentais sobre metodologias ágeis e sobre o Scrum. A seção 3 detalha a proposta de implantação do Scrum utilizando a ferramenta Asana e o Google Planilhas. A seção 4 apresenta um relato de experiência sobre o uso do Scrum no dia a dia da equipe do Nead da UCEFF, enquanto que a seção 5 conclui o trabalho.

\section{2 - Motivação e Conceitos Fundamentais}

A fim de possibilitar uma compreensão melhor do que motivou a aplicação da metodologia Scrum na equipe do Nead da UCEFF, abordaremos nessa seção um breve relato sobre o surgindo dessa equipe multidisciplinar e geograficamente distante. Além disso, faremos uma explanação sobre os principais conceitos sobre metodologias ágeis, enfatizando os principais eventos que compõem o Scrum.

\section{1 - Estruturação da equipe do Nead na UCEFF}

A história da EaD na UCEFF, campus Chapecó, teve início em 2008, quando iniciou-se a oferta de disciplinas semipresenciais em apenas alguns cursos presenciais da IES. No ano seguinte, em 2009, o Nead foi constituído com o objetivo de aprimorar a oferta das disciplinas semipresenciais. Para isso, a equipe era responsável por acompanhar o desenvolvimento das aulas, pesquisar sobre as possibilidades da modalidade a distância e capacitar os docentes para as atividades relacionadas à EaD.

A partir das experiências desenvolvidas ao longo dos anos com a oferta das disciplinas semipresenciais e da evolução e consolidação do modelo EaD, a IES decidiu solicitar o credenciamento para oferta de cursos de graduação e pós-graduação na modalidade a distância. Para isso, a equipe do Nead foi ampliada e passou a ser composta por uma equipe multidisciplinar.

Neste cenário, além da inserção de projetos para a viabilização da oferta de cursos na nova modalidade, houve uma expansão da atuação da equipe em novas disciplinas semipresenciais, assim como a atuação da equipe em capacitações docentes e discentes para ampliação do uso do Ambiente Virtual de Ensino e Aprendizagem (AVEA) como apoio às disciplinas presenciais. No caso, o AVEA utilizado foi o Moodle, que passamos a chamar de UCEFF Connect.

Todo esse cenário foi amplificado com o processo de unificação da UCEFF com o Centro Universitário FAl, de Itapiranga, que também já tinha sua história de EaD e passava pelo mesmo processo de expansão que a UCEFF de Chapecó, caminhando 
para o credenciamento para oferta de cursos na modalidade a distância. A partir desta unificação, todos os esforços teriam que ser conjuntos e as duas equipes passaram a trabalhar juntas.

O NEaD da UCEFF é responsável pela gestão e acompanhamento de todos os projetos de graduação, pós-graduação e extensão que envolvem o uso do AVEA, produção de materiais didáticos, produções audiovisuais, capacitações sobre o uso do AVEA, revisão de conteúdos tanto para o ensino presencial quanto para o ensino híbrido e a distância. A postagem de aulas de disciplinas interdisciplinares, semipresenciais, apoio a disciplinas presenciais, criação e edição de vídeo aula ou tutorial, revisão textual e gramatical de materiais enviados por professores ou tutores das disciplinas, criação de planilhas de apoio e acompanhamento das disciplinas oferecidas pela IES, estão entre as atividades desenvolvidas pela equipe.

\section{2 - A metodologia ágil Scrum}

O Scrum é um framework que surgiu nos anos 90 e vem sendo utilizado no gerenciamento e desenvolvimento de projetos de produtos nos mais variados níveis de complexidade (SCHWABER e SUTHERLAND, 2017). Por demonstrar uma alta efetividade aliada à praticidade de gestão, o Scrum passou a ser utilizado muito além do desenvolvimento de produtos, mas também no desenvolvimento de serviços e até na gestão de empresas.

O time Scrum é composto por um product owner, o time de desenvolvimento e um scrum master. Times scrum são auto-organizáveis e multifuncionais, possuindo a autonomia de escolher qual a melhor forma para completarem seu trabalho, em vez de serem dirigidos por outros de fora do time (SCHWABER e SUTHERLAND, 2017). Ainda de acordo com SCHWABER e SUTHERLAND (2017), o Scrum prescreve quatro eventos formais para inspeção e adaptação: planejamento do Sprint, reunião diária, revisão do Sprint e retrospectiva do Sprint. É responsabilidade do product owner, ou dono do produto, organizar uma lista de requisitos necessários para o projeto em questão. Essa lista é chamada de Product Backlog. Os itens presentes nessa lista devem ser constantemente atualizados e ranqueados pelo nível de prioridades. O Scrum trabalha com ciclos de produção onde cada um desses ciclos é nomeado de Sprint. A lista de atividades a serem realizadas em uma Sprint é denominada Sprint Backlog.

O planejamento do Sprint é o evento na qual as atividades mais prioritárias são estimadas para serem realizadas durante o próximo Sprint. É papel do Scrum Master coordenar esse evento, garantindo o equilíbrio entre os interesses do dono do produto e 
do time de desenvolvimento. Durante o desenvolvimento do Sprint, a equipe deve se reunir para uma reunião diária de curta duração, com no máximo 15 minutos, na qual cada integrante deve responder a três perguntas: $O$ que você fez ontem para ajudar a equipe a concluir o Sprint? O que você fará hoje para ajudar a equipe a concluir o Sprint? Quais obstáculos estão atrapalhando a equipe?

Ao final do Sprint a equipe se reúne para realizar a reunião de revisão do Sprint. É nesse momento que o time de desenvolvimento mostra 0 que foi alcançado durante 0 Sprint e o projeto é avaliado em relação aos objetivos do Sprint (TELES e MELLO, 2008). Na reunião de retrospectiva, que ocorre ao final de um Sprint, serve para identificar o que funcionou bem, o que pode ser melhorado e que ações serão tomadas para melhorar. Neste momento, cada integrante da equipe contribui com o seu ponto de vista sobre o Sprint que se encerrou.

A fim de facilitar a visualização das atividades do Sprint Backlog, é comum a utilização do quadro Kanban, que é um método de gestão visual que visa aumentar a eficiência da produção e otimizar seus sistemas de movimentação, produção, realização de tarefas e conclusão de demandas (MOURA, 2003). O quadro Kanban caiu como uma luva para o Scrum porque garante a transparência e a inspeção, dois dos pilares que suportam 0 framework. A transparência é garantida no momento em que todas as partes interessadas em um determinado projeto podem acompanhar, a qualquer momento, como está o desenvolvimento de cada atividade e os problemas encontrados nelas. A inspeção é possível na interpretação do mesmo: muitas atividades pendentes podem indicar problemas, assim como uma atividade que está há muito tempo sendo feita. A interpretação do quadro pode levar a diagnosticar problemas complexos muito facilmente, de forma visual e intuitiva.

\section{3 - Modelo de implantação do Scrum}

O processo de implantação de metodologias ágeis proposto neste trabalho teve início com a pesquisa e análise de ferramentas que permitissem o gerenciamento e organização de atividades de uma forma gráfica e intuitiva. A ferramenta a ser escolhida deveria satisfazer as necessidades de toda equipe e seus gestores. Para isso, ela deveria possuir recursos que permitissem aos gestores criar projetos, tarefas e subtarefas e classificá-las por contexto, tipo e prioridade. Além disso, a ferramenta deveria disponibilizar um quadro de tarefas, dividido por diferentes colunas, no qual os integrantes da equipe pudessem arrastar uma tarefa de uma coluna para a outra.

Após alguns testes e análises, a ferramenta escolhida foi a Asana. Trata-se de um 
aplicativo disponível tanto para web como para mobile, projetado para ajudar as equipes a organizar, rastrear e gerenciar seu trabalho. O principal motivo para essa decisão foi o fato da Asana ser uma ferramenta gratuita, flexível e de fácil usabilidade.

O primeiro passo para configurar a Asana é a criação dos projetos fixos de contextos. Esses projetos são utilizados para classificar as atividades a serem realizadas em contextos que facilitem sua compreensão. Recomenda-se que o gestor realize uma breve análise das principais atividades que sua equipe já realizou e tente classificá-las em diferentes contextos para então criar os projetos na ferramenta. Esses projetos fixos de contextos compõe o product backlog. Dentro de cada projeto fixo de contexto, as demandas que forem surgindo deverão ser adicionadas e classificadas de acordo com seu tipo e prioridade. Para realizar essa classificação, utilizamos o recurso de Tags. As Tags utilizadas para classificar uma atividade de acordo com seu tipo são: História; Tarefa e Problema. Enquanto que as Tags utilizadas para classificar a prioridade de cada item são: Muito Alta; Alta; Média, Baixa, Muito Baixa. Para adicionar as Tags em uma atividade, deve-se abrir a atividade, clicar em mais ações e depois em Tags.

A cada nova Sprint, a fim de montar o Sprint Backlog, deve-se criar um novo projeto, utilizando o layout de quadro (Board). Durante a reunião de planejamento, as atividades mais importantes de cada lista de contexto são acrescentadas ao sprint backlog. Para isso, deve-se clicar na atividade presente no product backlog e adicioná-la, também, ao projeto recém criado da Sprint. O quadro do projeto da Sprint deverá ser configurado para conter apenas as colunas que atendam as demandas da equipe. Para uma equipe multidisciplinar como é o caso da equipe do $\mathrm{NEaD}$, sugere-se a utilização das seguintes colunas:

- Para Fazer: Etapa inicial na qual todas atividade são inicialmente acrescentadas.

- Pendente: Atividades que possuem alguma pendência para poder ser realizada. A eliminação dessa pendência deve ser prioridade do gestor da equipe.

- Em Progresso: Atividades que estão em andamento. Recomenda-se que cada integrante da equipe tenha apenas uma tarefa em progresso por vez.

- Para Validação: Atividade que precisam ser validadas por outros integrantes da equipe, pelo gestor ou por outras partes interessadas, como professores e tutores.

- Para Refazer: Atividades que não passaram pela validação e que necessitam de ajustes.

- Concluído: Atividades que foram concluídas e sinalizadas como prontas.

Após finalizar a configuração da ferramenta, notou-se a necessidade da criação de uma 
planilha para gerenciamento de horas estimadas e realizadas e acompanhamento do gráfico Burndown da Sprint. Para isso, utilizou-se o Google Planilhas, que pôde facilmente ser disponibilizado na descrição de cada projeto de Sprint na Asana. A Figura 1 , a seguir, ilustra parte da planilha criada.

Figura 1: Parte da planilha utilzada para o gerenciamento da disponibilidade de cada integrante da equipe.

\begin{tabular}{|c|c|c|c|c|c|c|c|c|c|c|c|}
\hline & B & c & D & E & $\mathrm{F}$ & G & $\mathrm{H}$ & 1 & J & K & L \\
\hline 1 & & & & & & & & \multicolumn{4}{|c|}{ Sprint N } \\
\hline \multicolumn{12}{|c|}{ thor } \\
\hline 3 & & Data Inicio & Data Fim & & & & & & & & \\
\hline 4 & Período & $02 / 05 / 2018$ & $15 / 05 / 2018$ & & & & & & & & \\
\hline 5 & Total & 10 & dias úteis & & & & & & & & \\
\hline \multicolumn{12}{|l|}{6} \\
\hline 7 & Equipe & $\begin{array}{c}\text { Dias } \\
\text { semanais }\end{array}$ & $\begin{array}{l}\text { Horas } \\
\text { Diarias }\end{array}$ & $\begin{array}{c}\text { Total de } \\
\text { Horas }\end{array}$ & Descontos & Planejamento & $\begin{array}{l}\text { Reuniões } \\
\text { Diárias }\end{array}$ & $\begin{array}{l}\text { Saldo para } \\
\text { Atividade }\end{array}$ & Foco & $\begin{array}{c}\text { Horas Previstas } \\
\text { para } \\
\text { Atividades }\end{array}$ & $\begin{array}{c}\text { Horas } \\
\text { Estimadas }\end{array}$ \\
\hline 8 & Integrante 1 & $=\$ C \$ 5$ & $=44 / 5$ & $=\mathrm{D} 8 * \mathrm{C} \$ 5$ & 0 & 4 & $=(C \$ 5-2) * 15 / 60$ & $=E 8-F 8$ & 0,7 & $=\mid 8 * 18$ & 55 \\
\hline 9 & Integrante 2 & $=\$ C \$ 5$ & $=44 / 5$ & $=\mathrm{D} 9 * \mathrm{C} \$ 5$ & 0 & 4 & $=(C \$ 5-2) * 15 / 60$ & =E9-F9 & 0,7 & $=19 * 19$ & 55 \\
\hline 10 & Integrante 3 & $=\$ C \$ 5$ & $=44 / 5$ & $=\mathrm{D} 10 * \mathrm{C} \$ 5$ & 0 & 4 & $=(C \$ 5-2) * 15 / 60$ & $=\mathrm{E} 10-\mathrm{F} 10$ & 0,5 & $=\mid 10 *\rfloor 10$ & 55 \\
\hline 11 & $\ldots$ & $\ldots$ & $\ldots$ & $\ldots$ & $\ldots$ & $\ldots$ & $\ldots$ & $\ldots$ & $\ldots$ & $\ldots$ & $\ldots$ \\
\hline 12 & Total & & & & & $=\mathrm{SOMA}(\mathrm{G} 8: \mathrm{G} 11)$ & ) $=\mathrm{SOMA}(\mathrm{H} 8: \mathrm{H} 11)$ & & & $=\mathrm{SOMA}(\mathrm{K} 8: \mathrm{K} 11)$ & =SOMA(L8:L11) \\
\hline
\end{tabular}

Fonte: o autor.

Ainda nessa planilha, implantou-se uma tabela para acompanhamento de horas planejadas vs. atual e a geração automática do gráfico burndown. Essa tabela deve ser atualizada diariamente após a reunião diária, informando o número de horas concluídas durante o último dia de trabalho da equipe.

Para finalizar o processo, a equipe deve ser capacitada. Para isso, recomenda-se uma apresentação sobre o Scrum, enfatizando os principais eventos necessários para seu funcionamento. Depois, deve-se ser realizada uma simulação, utilizando as ferramentas já configuradas, de todo processo de planejamento de uma Sprint. Além da equipe, é importante que a direção e demais setores também passam a conhecer a forma de trabalho que a equipe passará a adotar. Deve-se ser enfatizado o ciclo de cada Sprint e a forma de divulgação após cada reunião de planejamento. Isso é importante para tentar evitar atividades extras, que poderão impactar a entrega das atividades da Sprint.

\section{4 - Scrum na prática no dia a dia da equipe do NEAD da UCEFF}

Aplicar o Scrum na prática traz várias mudanças para uma empresa, inclusive mudanças de cultura. A primeira ação para implantação do Scrum no NEaD foi a capacitação para que todos os envolvidos no processo pudessem conhecer as atividades a serem desempenhadas na nova metodologia de gerência de projeto e assim nivelar o 
conhecimento adquirido por parte equipe. Durante a capacitação foram repassadas facilidades e vantagens proporcionadas pelo Scrum e explicações sobre o ciclo de desenvolvimento da metodologia ágil com os detalhes de cada ação a ser executada.

A flexibilidade do uso do Scrum permite aos gestores do NEaD definirem as reuniões de planejamento com até 6 meses de antecedência. Trata-se de um cronograma essencial para a organização de uma equipe multidisciplinar que dispõe de membros com diferentes cargas horárias e específicas habilidades nas unidades de Itapiranga e Chapecó. No dia da reunião de planejamento, um membro de cada unidade fica responsável por organizar a estrutura física necessária para realização da webconferência, constituída por uma televisão, um notebook e uma webcam de boa qualidade. A comunicação síncrona é realizada por meio da ferramenta Hangouts, do Google. Durante essa webconferência são realizados dois eventos da Sprint: a reunião de retrospectiva e a reunião de planejamento. No primeiro momento, todos o membros contribuem com os pontos positivos e os pontos negativos observados. O segundo momento é a análise das atividades em destaque do product backlog (atividades com maior prioridade). É papel do gestor apontar para equipe quais atividades devem ser realizadas com urgência ou preferencialmente. A terceira fase do planejamento é elencar o tempo que cada participante irá precisar para realizar suas atividades e se necessário a equipe toda participa votando um tempo estimado.

A organização do product backlog é organizado em quatro projetos fixos de contexto na Asana, chamados: Demandas Moodle - BACKLOG; Demandas do NEaD - BACKLOG; Produção de Conteúdos - BACKLOG; e Capacitações - BACKLOG. Durante a fase que antecede a reunião de planejamento da Sprint as atividades são inseridas nos respectivos projetos e classificadas para indicar sua origem e a qual unidade devem atender: Chapecó - XAP ou Itapiranga - ITG. As atividades que serão desenvolvidas nas duas unidades são classificadas como XAP/ITG. Além desta classificação, todas as atividades recebem uma tag que identifica o tipo da atividade. Na descrição de cada atividade são descritas as informações necessárias para a execução da mesma.

Durante a reunião de planejamento da Sprint as atividades são classificadas por ordem de prioridade e adicionadas ao projeto do Sprint Backlog. Além disso, ainda durante a reunião de planejamento, a planilha da Sprint é atualizada com o período e a duração do Sprint, que possuem na média de quinze dias, o total de horas estimadas, bem como a disponibilidade dos integrantes do time de desenvolvimento. Por uma questão de organização, as Sprints são numeradas na Asana em ordem crescente, como por exemplo: Sprint10_BACKLOG. 
O quadro da Sprint segue a organização sugerida anteriormente, com o acréscimo de uma coluna para atividade extras. A primeira instância do quadro (da esquerda para a direita) representa o start do processo de desenvolvimento das atividades até a sua conclusão, com exceção para a instância Atividade Extra na qual são incluídas atividades que não foram estimadas no Sprint, porém, necessitam ser executadas. A Figura 2 apresenta o layout customizado da ferramenta para melhor se adaptar ao formato de trabalho do NEaD. No menu lateral ficam disponíveis todos os projetos e repositórios de tarefas, na área de trabalho estão as colunas de acompanhamento que permitem a qualquer membro da equipe analisar e acompanhar as atividades podendo assim auxiliar ou até mesmo realizar novas tarefas.

Figura 2: Exemplo de uso da ferramenta Asana ao longo de um Sprint.

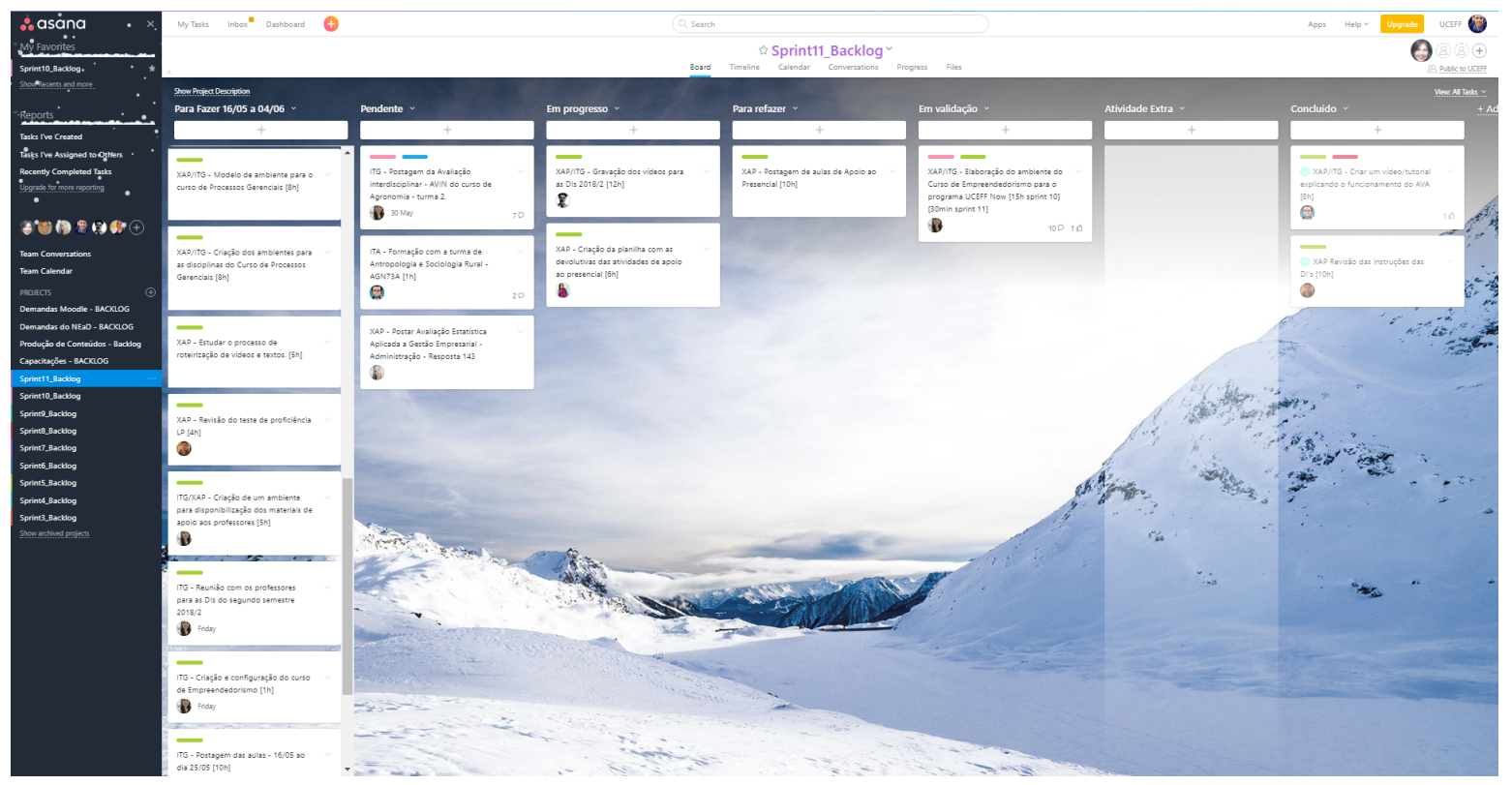

Fonte: o autor.

Após a conclusão dessas etapas cada integrante da equipe inicia suas atividades buscando seguir o tempo estimado e o cronograma previsto, diariamente as tarefas finalizadas são atualizadas na planilha de acompanhamento da Sprint, permitindo o acompanhamento: da execução das atividades, situação e conclusão das atividades com suas respectivas horas. Além do acompanhamento do quadro de atividades realizado pela Asana, a equipe realiza reuniões diárias de acompanhamento do Sprint, nas quais todos os integrantes da equipe devem responder às questões padrão do Scrum. Após a reunião diária as horas-atividade concluídas são lançadas na planilha de acompanhamento para visualização do gráfico burndown.

\section{5 - Conclusões}


Metodologias de projetos permitem ao gestor dos negócios gerenciar e acompanhar em tempo real o andamento das tarefas e etapas do seu projeto. O Scrum é uma metodologia que vem se destacando pela forma como organiza as equipes de trabalho e cada etapa do projeto, permitindo a qualquer empresa fazer uso desse modelo em projetos de diferentes níveis de complexidade.

A aplicação da metodologia Scrum no NEaD não somente implementou um nível maior de gestão nos projetos, mas permitiu também o trabalho conjunto de equipes localizadas em diferentes cidades aumentando a comunicação, entendimento, desempenho e objetividade na conclusão das atividades. A partir da implantação do Scrum se observou que a equipe do NEaD evoluiu profissionalmente, tornando-se mais integrada e demonstrando maior segurança em relação à capacidade de estimativa de tempo e autogestão, descartando a necessidade de atribuição de tarefas pelo gestor. Cabe destacar uma considerável melhora na comunicação entre os integrantes da equipe do NEaD de Chapecó e Itapiranga. As retrospectivas realizadas nas reuniões demonstram a aceitação do Scrum pelos integrantes da equipe. Todos estão interessados em melhorar o processo e sempre apresentam sugestões para intensificar a aplicação da metodologia, como por exemplo, a inclusão de uma coluna no quadro para 0 acompanhamento das atividades extras.

Como sugestão para trabalhos futuros entende-se que este trabalho pode ser melhorado com o desenvolvimento de uma análise quantitativa da eficiência do uso do Scrum na IES e também por meio da aplicação do estudo em outras equipes e/ou organizações com equipes multidisciplinares.

\section{6 - Referências}

MOURA, Reinaldo Aparecido, 2003.Kanban a Simplicidade do Controle da Produção. Ed. IMAM, São Paulo, Brasil.

SCHWABER, Ken; SUTHERLAND, Jeff. Guia do Scrum. 2017.

SUTHERLAND, Jeff. Scrum: a arte de fazer o dobro do trabalho na metade do tempo. Leya, 2016.

TELES, V. M.; MELLO, L. Desenvolvimento Ágil. 2008. Disponível em: $<$ http://www.desenvolvimentoagil.com.br/scrum/>. Acesso em: 20 de maio de 2018. 